\title{
Microstructural Evolution and Hot Deformation Behavior of Lean Duplex Stainless Steel 2101
}

\author{
Haijian XU, ${ }^{1,2,3)}$ Wanqing $\mathrm{HU}^{11}{ }^{1)}$ Chao KANG, ${ }^{3)}$ Weijuan $\mathrm{LI}^{1 / *}$ and Xiaochun SHA ${ }^{3)}$ \\ 1) State Key Laboratory of Metal Material for Marine Equipment and Application, Ansteel Group Corporation, Anshan, 114009 \\ P.R. China. \\ 2) School of Materials and Metallurgy, University of Science and Technology Liaoning, Anshan, 114051 P.R. China. \\ 3) Angang Steel Company Limited, Anshan, 114009 P.R. China.
}

(Received on September 8, 2020; accepted on November 10, 2020)

\begin{abstract}
In this study, hot deformation behavior of lean duplex stainless steel 2101 (LDX2101) is investigated via isothermal compressive tests in the temperature ranges of $900-1150^{\circ} \mathrm{C}$ and the strain rate ranges of $0.01-10 \mathrm{~s}^{-1}$. The effect of temperature and strain rate on the hot workability, strain partitioning and flow behaviour of LDX2101 is systematically investigated. It is found that the peak stress decreased with an increase in deformation temperature and a decrease in strain rate. The softening mechanism of the ferrite and austenite is dynamic recovery (DRV) and dynamic recrystallization (DRX), respectively. Further increasing the strain rate promote the DRX. The hot processing map was constructed in the sample. There are two flow instability regions at lower strain rate and lower temperature due to the lack of sufficient extra stress for the discrepancy of deformation coordination between the ferrite/austenite phases. Moreover, brittle $\mathrm{Cr}_{2} \mathrm{~N}$ precipitates are observed along the ferrite/austenite phase boundaries, which can act microcracks initiation position. Considering the hot processing map and microstructural evolution in LDX2101, the optimum hot processing parameters for LDX2101 are found to be in a strain rate range of $0.01-10 \mathrm{~s}^{-1}$ with the temperature range of above $1050^{\circ} \mathrm{C}$ and strain rate of $0.8-10 \mathrm{~s}^{-1}$.
\end{abstract}

KEY WORDS: lean duplex stainless steel; hot deformation; processing map; microcracks; $\mathrm{Cr}_{2} \mathrm{~N}$ precipitates.

\section{Introduction}

Duplex stainless steel (DSS) owns an attractive combination of mechanical properties, good weldability as well as superior localized corrosion resistance. It can be considered as the main alternatives to single ferritic and austenitic stainless steels in fusion reactor spent fuel tanks. ${ }^{1-4)}$ It is well known that the excellent property of DSSs relies on a approximately equal proportion of face-centered cubic austenite and a body-centered ferrite phases. ${ }^{5)}$ The mechanical properties and thermal expansion coefficient of austenite and ferrite differ from each other due to the inhomogeneous strain distribution between the two constituent phases during hot deformation. ${ }^{6}$ This can lead to surface defects and edge cracks in hot-rolled DSS products. Lean DSS 2101 (LDX2101) has attracted much attention in recent years by replacing expensive nickel $(\mathrm{Ni})$ with cheaper $(\mathrm{Mn})$ and nitrogen $(\mathrm{N})$ compared to the common DSS. However, the higher content of interstitial atomic $\mathrm{N}$ induces precipitation of brittle $\mathrm{Cr}_{2} \mathrm{~N}$ precipitates and increase in the hardness discrepancy between the two phases at high temperature

\footnotetext{
* Corresponding author: E-mail: liweijuan826@163.com
}

deforming. ${ }^{7-9)}$ Hence, the deformation coordination of ferritic and austenitic phases or the $\mathrm{Cr}_{2} \mathrm{~N}$ precipitates and ferritic/austenitic phases are worse and the edge cracking and surface defects are more likely to initiate in the LDX2101 than traditional DSS (DSS2205) during hot deformation. Therefore, it is vital to investigate the deformation behaviors and microstructural evolution of LDX2101 in more detail in order to find an effective way to control the microstructure and deforming coordination and thus enhance the quality of the products.

The deformation mechanisms of austenite and ferrite during hot deformation differ obviously. Ferrite has a high stacking fault energy (SFE), which can make dislocations climb or crossslip easily, and therefore undergoes dynamic recovery (DRV) and other microstructural evolution during deformation. However, austenitic undergoes a limited DRV due to the relatively low SFE, and therefore occurs dynamic recrystallization (DRX), when the driving force once exceeds a critical value in austenite. ${ }^{10-13)}$ The deformation coordination will be non uniform between the two phases in a duplex microstructure. It is found that the majority of strain is concentrated in ferrite at low strain rate during deforming. Therefore it leads the poor deformation compat- 
ibility between the two phases, and increases the difficulties of the flow behavior of DSSs. The dominant deformation mechanism of DSSs has always been controversial in this aspect. $^{14-17)}$

Some groups found that austenite and ferrite in DSSs was softened by their own softening mechanism as in the corresponding single phase alloys. ${ }^{11,13)}$ However, Zou found the softening mechanism of the ferrite would be DRX in DSSs. ${ }^{18)}$ Fan suggested that only DRV occurred due to the inhibition DRX in DSS2205. ${ }^{19)}$ Moreover, Liu pointed that both ferrite and austenite were softened by DRX. ${ }^{20)}$ In this regard, the effect of deformation parameters (temperature, strain rate) actually should be considered as one of the most critical influences on the softening mechanism of the alloy. However, there are few reports with this respect to this cause. So, investigations on the characteristics of flow curves and relevant microstructural evolution during hot deforming become vital and significant.

The hot workability, microstructure and product quality in stainless steels are obviously controlled by hot deformation parameters and brittle precipitates in the matrix. ${ }^{21-23)}$ Improper processing regimes of hot deformation can lead to abominable hot workability of the products. Processing map is often applied to research the hot workability for metals in order to avoid the occurrence of flow instability regions in hot working processes. Liu et al. ${ }^{24)}$ investigated the effect of true strains on the processing maps of a Nickle base superalloy and found that the proper hot deformation parameters could get fine homogeneous microstructure. Ma et l. $^{25)}$ studied the effect of strain and temperatures on the processing maps of DSS 2205 and confirmed that high strain rate and low deformation temperature widened flow instability region and deteriorates the hot workability of the alloys.

Up to now, the edge cracking and an inappropriated surface defects during hot deforming conditions of LDX2101 have not yet been completely solved. ${ }^{26-28)}$ Many groups have investigated the effect of phase ratio on the thermal plasticity of these steels. ${ }^{29,30}$ They found that the plasticity of ferritic was better than austenitic, but both were significantly weakened by the presence of brittle precipitates at high temperature stage. However, the optimal processing parameters and the effect of strain rate, temperature and microstructural evolution on the hot workability of LDX2101 require further systematically investigation.

In the present work, to study the deformation parameters and relevant microstructural evolution of LDX2101 in influencing on the optimal processing parameters in actual production, we carried out hot uniaxial compression tests under varying deformation states to investigate the effects of strain rate, and deformation temperature on the flow behavior of LDX2101 by processing maps and verify the relation between the flow behavior and microstructural evolution.

\section{Experimental}

The experimental steel applied for our experiments was LDX2101 produced by Ansteel Group Corporation Limited, which has a composition of Fe-0.023C-0.59Si4.91Mn-0.02P-0.001S-1.62 Ni-21.5Cr-0.26Mo-0.221N (mass\%). The thermo- mechanical procedure adopted on the samples is shown in Fig. 1(a). The cylindrical compression samples of $12 \mathrm{~mm}$ in height and $8 \mathrm{~mm}$ in diameter were fabricated from the billet, which was isothermally compressed on a thermal-mechanical simulator Gleeble- 3800 . The samples were first heated up to $1220^{\circ} \mathrm{C}$ at the rate of $10^{\circ} \mathrm{C} / \mathrm{s}$ and then kept for $300 \mathrm{~s}$ to homogenize microstructure. Figure 1(b) shows the microstructure of the preheated sample before hot deformation, in which the light and dark grey areas represent austenite and ferrite phases, respectively. It can be seen that the approximately acicular and massive austenite are embedded in the ferrite matrix. The volume fraction of ferrite phases is measured to be about $55 \%$. Then, samples were cooled to the preset temperature at $5^{\circ} \mathrm{C} / \mathrm{s} \mathrm{s}$ and held for $30 \mathrm{~s}$ to eliminate the thermal gradient before the compression tests. Specimens were compressed to the true strain of 0.7 at a strain rate range of $0.01-10 \mathrm{~s}^{-1}$, temperature ranges of $900-1150^{\circ} \mathrm{C}$. After hot deformation, the specimens were water quenched by room temperature to retain the deformation microstructure.

The deformed specimens in different conditions were cut in a center position at the hoop surface of compression. Based on stress state analysis, secondary tension can develop during hot compression and micro-cracks may initiate at the hoop surface when the deformation amount exceeds a critical hoop strain in LDX2101.7) The value of strain is nearly to the total strain of 0.7 in this position. The deformation distributions in LDX2101 in different conditions were determined using by Electron backscattered diffraction (EBSD) with a step size of $1 \mu \mathrm{m}$. The EBSD samples were mechanical polished and then electro-polished
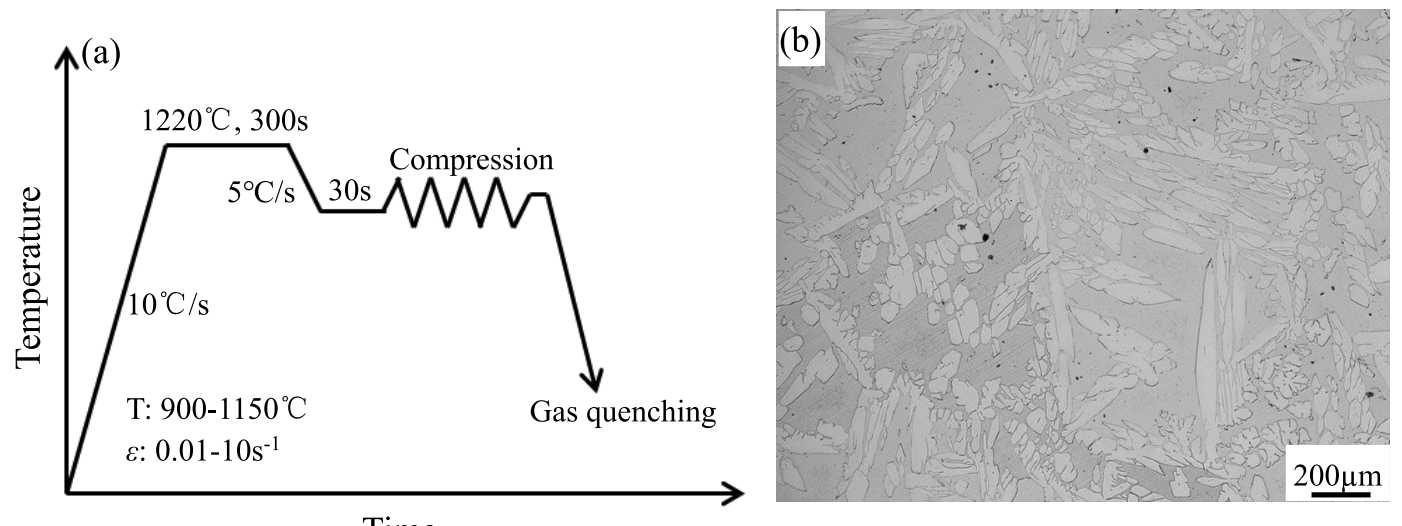

Time

Fig. 1. (a) Schematics of hot compression test and (b) initial microstructure of LDX2101. 
by electrolytic polishing with $10 \% \mathrm{HClO}_{4}+90 \%$ glacial acetic acid solution in order to remove the deformation layer introduced during mechanical milling. In order to study the mechanism of hot deforming cracking in the samples, the microstructures of the cracks were examined using optical microscope (Vert.A1 OM, Zeiss) and field emission scanning electron microscope (JSM7100F FE-SEM, JEOL). Samples for OM and SEM were prepared by mechanically milled, polished, finally etched with aqua regia. In addition, transmission electron microscopy (TEM) thin disks were prepared by electropolishing at $20 \mathrm{~V}$ in a solution of $10 \%$ $\mathrm{HClO}_{4}+20 \% \mathrm{C}_{2} \mathrm{H}_{5} \mathrm{OH}$ at about $-20^{\circ} \mathrm{C}$ for $10 \mathrm{~s}$. The dislocation evolutions and crystal of precipitates in LDX2101 were examined using TEM (2100F, JEOL) with a double tilt specimen holder.

\section{Results and Discussion}

\subsection{True Stress-Strain Curves}

Figure 2 shows the true stress-strain curves of LDX2101 obtained from hot compression testing at different temperatures under various strain rates. It can be seen that the flow stress decreases with the increase in temperatures and decrease in strain rates. At the initial deformation stage, the flow stress rapidly increased due to strain-hardening mechanism, which may increase the dislocation density during hot deforming. ${ }^{31)}$ Subsequently, the strain-hardening rate gradually decreased until the flow stress reached a maximum value. After that, the flow stress slightly decreased due to the softening of DRV and DRX. Meanwhile, the flow curves within the temperatures range of exhibit softening characterization after a peak stress, this phenomenon is more obvious with the increase in strain rate, indicating that a typical DRX has occurred during hot deformation. When the compression is performed at $0.01 \mathrm{~s}^{-1}$ with all the testing temperatures, a steady state deformation occurs due to the DRV. By comparison, as strain rate increases at different temperatures, the flow stress declines continuously even at the last stage of deformation. Thus, it can be concluded that strain rates and temperatures are the main factors that affect the flow behavior and microstructural evolution of LDX2101 during hot deformation.

\subsection{Establishment of Constitutive Equation/Processing Maps}

In order to explore the difference in peak stresses of LDX2101 between strain rates and deformation temperatures, their peak stresses were compared, as presented in Fig. 3. The peak stresses of the LDX2101 deformed at $1150^{\circ} \mathrm{C}$ with strain rate of $10 \mathrm{~s}^{-1}$ were measured to be about $103.1 \mathrm{MPa}$, which was higher than those samples deformed at strain rate of $0.01 \mathrm{~s}^{-1}$ with any testing temperatures. With increasing the strain rates and/or decreasing the hot deformation temperatures, the peak stress was found to be increased. The peak stresses increases with increasing strain rates, which indicated that the mechanism of work hardening transfers from dislocation storage to tangled dislocation structures. The higher amount of tangled dislocation structures could hinder dislocation movement and increase the deformation resistance. ${ }^{3)}$ As for the effect of deformation temperatures on the peak stresses, it is found that both the volume fraction of the harder austenite phases and the stress for dislocation movement decreased with enhancing temperatures in LDX2101, leading to softening of the samples. Moreover, the higher content of nitrogen $(\mathrm{N})$ can enhance the high temperature strength of LDX2101 and make it more
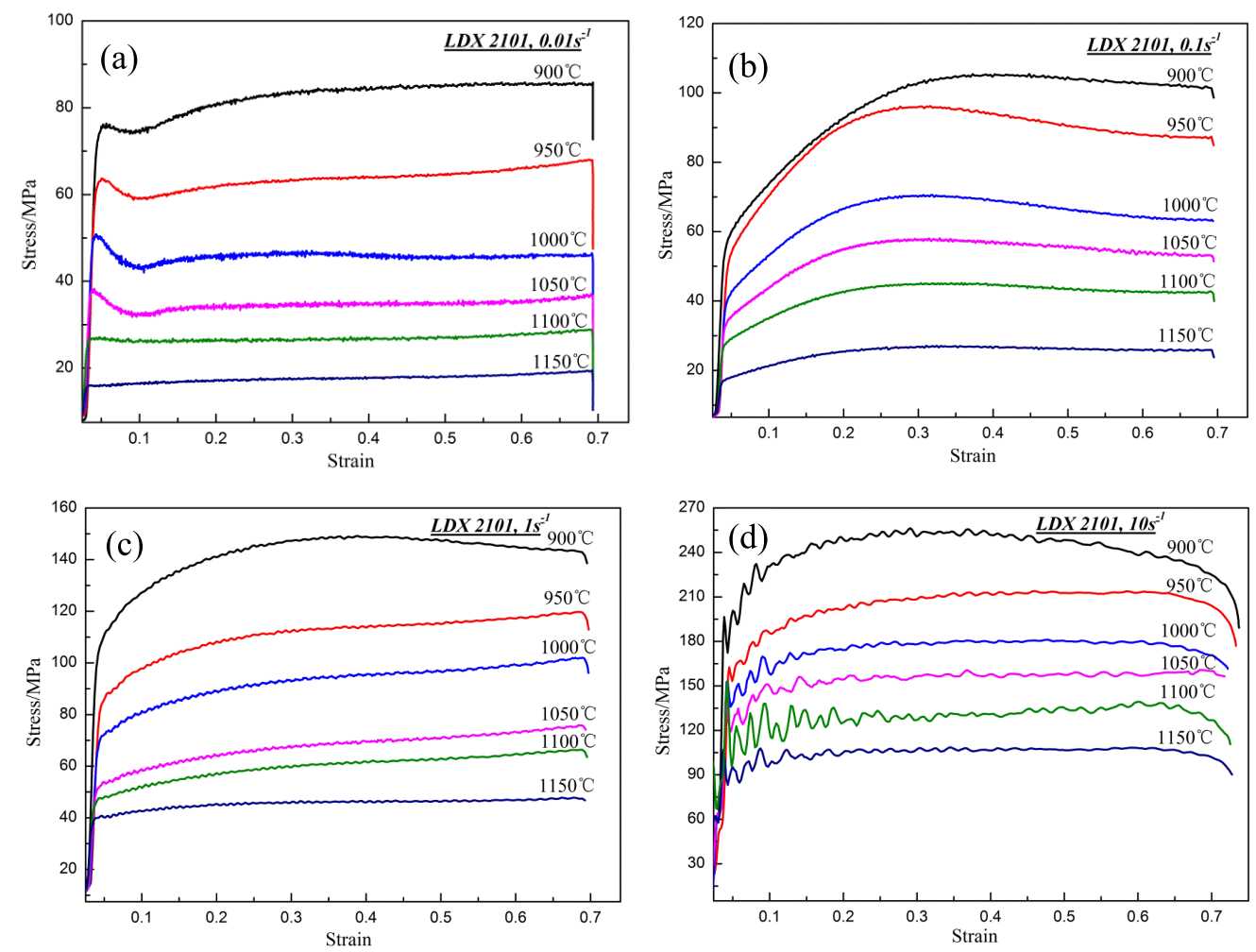

Fig. 2. True stress-strain curves of LDX2101 deformed under different deformation conditions (a) $0.01 \mathrm{~s}^{-1}$, (b) $0.1 \mathrm{~s}^{-1}$, (c) $1 \mathrm{~s}^{-1}$, (d) $10 \mathrm{~s}^{-1}$. (Online version in color.) 


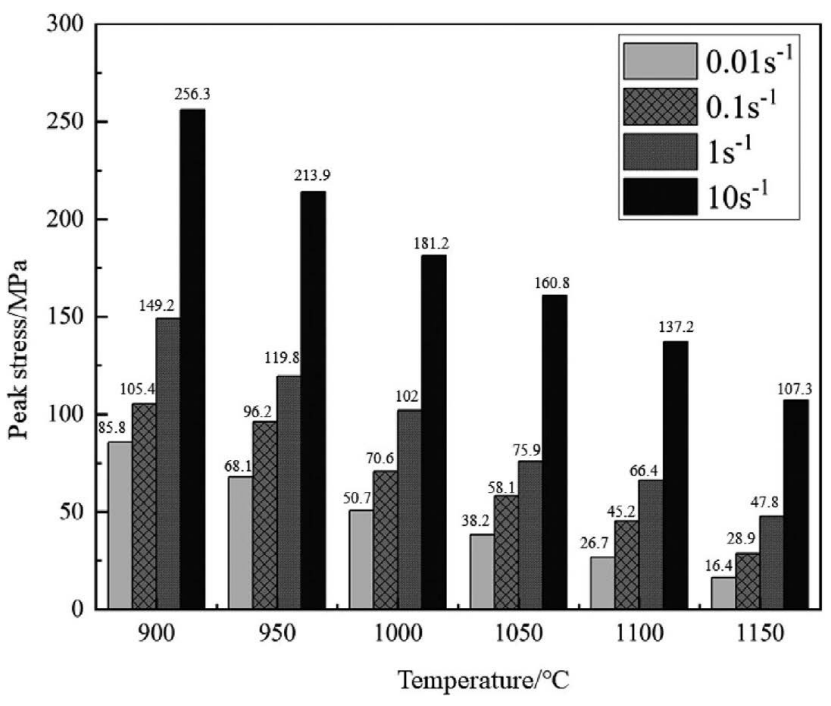

Fig. 3. The variation of peak stress vs. strain rates under different deformation temperatures of LDX2101.

difficult to deform as compared to conventional DSS2205 under the same hot deformation conditions. ${ }^{4)}$

The effects of deformation temperatures and strain rates on the flow behavior can be analyzed by the Arrhenius-type equation. ${ }^{9,16)}$ The equations can be expressed by the following methods for all, low and high stress levels, respectively at different levels of strains.

$$
\begin{array}{r}
\dot{\varepsilon}=\mathrm{A}[\sinh (\alpha \sigma)]^{n} \exp \left(-\frac{Q}{R T}\right) \\
\dot{\varepsilon}=B \sigma^{n_{1}} \ldots \ldots \ldots \ldots \ldots \ldots \ldots \ldots \ldots \ldots \ldots \ldots \ldots \ldots
\end{array}
$$

Where $\sigma$ is the peak stress, $Q$ is the apparent activation energy of the hot deformation corresponding to the peak stress, $\varepsilon$ is the strain rate, $\mathrm{R}$ is the gas constant $(8.3145 \mathrm{~J} /$ $\mathrm{mol} / \mathrm{K})$, and $A, B, C, \alpha, \beta$, and $n_{1}$ are material constants which need to be obtained by experiment; $\alpha$ value is calculated by $\beta$ and $n_{l}$.

After taking the logarithm on Eqs. (2) and (3), the following equations can be obtained:

$$
\begin{aligned}
\ln \sigma & =\frac{1}{n_{1}} \ln \dot{\varepsilon}-\frac{1}{n_{1}} \ln B \\
\sigma & =\frac{1}{\beta} \ln \dot{\varepsilon}-\ln C \ldots .
\end{aligned}
$$

By plotting $\ln \sigma$-ln $\varepsilon$ and $\sigma$-ln $\varepsilon$ (Figs. 4(a) and 4(b)), the $n_{1}$ and $\beta$ values were calculated to be 5.027 and 0.056 by linear fitting and calculating averages, respectively, and then $\alpha \approx \beta /$ $\mathrm{n} 1=0.011 \mathrm{MPa}^{-1}$.

In order to calculate the $n, A$ and $Q$ values, it is necessary to take the logarithm from Eq. (1), which shows:

$$
\ln [\sinh (\alpha \sigma)]=\frac{1}{n} \ln \dot{\varepsilon}+\frac{Q}{n R T}-\frac{1}{n} \ln A
$$

Assuming constant strain rate, and the Eq. (6) can be rewritten:

$$
Q=n R d\{\ln [\sinh (\alpha \sigma)]\} / d(1 / T)
$$

Figures 4(c) and 4(d) show the relationships of $\ln \left[\sinh \left(\mathrm{a} \sigma_{p}\right)\right]$ versus $\ln \varepsilon$ and $\ln \left[\sinh \left(\mathrm{a} \sigma_{p}\right)\right]$ versus $1000 / \mathrm{T}$, and the value of $n$ can be calculated as 3.6778 by the slope of $\ln \varepsilon-\ln \left[\sinh \left(a \sigma_{p}\right)\right]$ at different testing temperatures. Otherwise, the activation energy $Q$ was calculated to be about $323.3 \mathrm{~kJ} / \mathrm{mol}$ from the slope of $\ln \left[\sinh \left(\mathrm{a} \sigma_{p}\right)\right]-1000 / \mathrm{T}$.

Zener-Hollomon equation was employed to describe the relationships among flow stresses, strain rates, and temperatures based on the experimental results from the hot compression testing results, which can be established through constitutive equations of hyperbolic sine function. The Zener-Hollomon equation can be expressed by the following equation:

$$
Z=\dot{\varepsilon} \exp [Q / R T]=A[\sinh (\alpha \sigma)]^{n}
$$

By plotting $\ln Z$ against $\ln \left[\sinh \left(\mathrm{a} \sigma_{p}\right)\right]$, as shown in Fig. 4(e), the value of $A$ is calculated to be $2.74554 \times 10^{12}$. The constitutive equation at peak stress embracing the ZenerHollomon parameters of LDX2101 is expressed by substituting $a, n, Q$, and $A$ into Eqs. (1) and (8) as follows:

$$
\begin{gathered}
\dot{\varepsilon}=2.74554 \times 10^{12}[\sinh (0.011 \sigma)]^{3.51452} \exp \left(-\frac{32330}{R T}\right) \ldots \\
Z=A[\sinh (\alpha \sigma)]^{n}=2.74554 \times 10^{12}[\sinh (0.011 \sigma)]^{3.51452}
\end{gathered}
$$

In order to better predict the instability zone of hot deformation and optimize the process factors (temperatures and strain rates) of hot deforming, the processing maps of LDX2101 were constructed according to the hot workability approach at a true strain of 0.7 . According to the dynamic alloys modelling, the total energy absorbed by the workpiece during the processing dissipates mainly through the following two factors: the energy consumed by plastic deformation $(G)$ and the energy consumed by microstructural evolution $(J)$. Therefore, the ratio between $G$ and $J$ can be determined by the strain rates sensitivity $m$ as:

$$
\frac{\partial J}{\partial G}=\frac{\dot{\varepsilon} \partial \sigma}{\sigma \partial \dot{\varepsilon}}=\frac{\partial(\ln \sigma)}{\partial(\ln \dot{\varepsilon})}
$$

In order to determine the proportion of the energy consumed in microstructural evolution, a parameter $\eta$ is assigned to describe the value of power dissipation as follows:

$$
\eta=\frac{2 m}{m+1}
$$

A larger value of $\eta$ manifests that the proportion of the energy consumed in structural transformation is larger, and the softening effect is also activated. However in some cases, flow instability, including break, folds, etc., also enhances the value of $\eta$ when the processing parameters fall into the instability domain. Accordingly, the corresponding Prasad criterion $^{32)}$ can be expressed as follows:

$$
\xi(\dot{\varepsilon})=\frac{\partial \log \left(\frac{m}{m+1}\right)}{\partial \log \dot{\varepsilon}}+m<0
$$

A value of $\xi$ less than zero means that flow instability will happen when the variation of entropy in the system is less than the strain rate during hot deformation processing. 

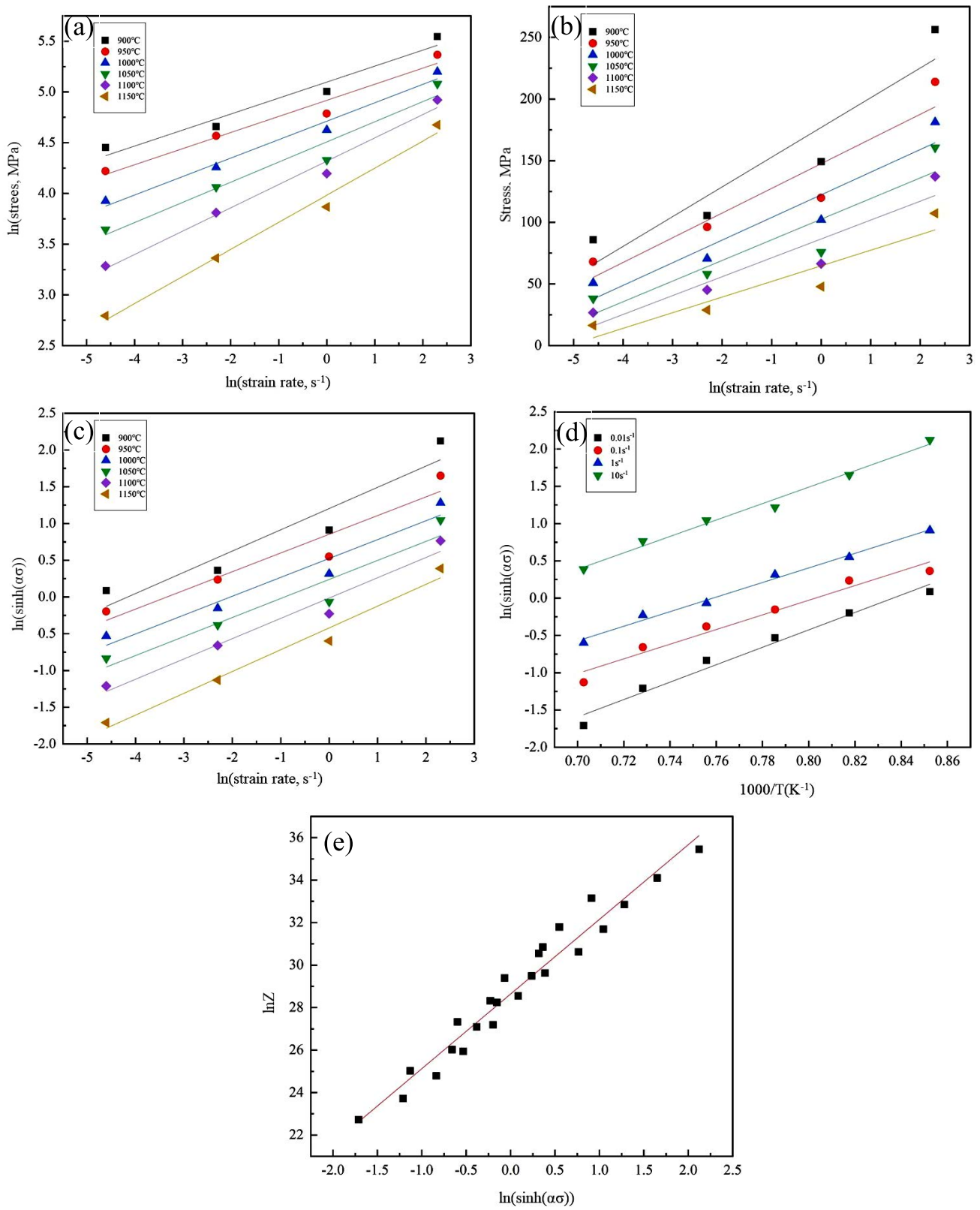

Fig. 4. Linear relationships of (a) $\ln \sigma-\ln \varepsilon$, (b) $\sigma$ and $\ln \varepsilon$, (c) $\ln [\sinh (\mathrm{a} \sigma)]$ and $\ln \varepsilon$, (d) $\ln [\sinh (\mathrm{a} \sigma)]$ and $1000 / T$, (e) $\ln Z$ and $\ln [\sinh (\mathrm{a} \sigma)]$ for LDX2101 at different deformation conditions. (Online version in color.)

Figure 5 presents the processing maps of LDX2101 a true strain of 0.7 , which shows that the flow instability regions appear at a low strain rate at the beginning of deformation. It corresponds to two regions: region 1 is located in the temperature ranges of $930-990^{\circ} \mathrm{C}$, with logarithm of strain rate range of $0.01-0.31 \mathrm{~s}^{-1}$, and region 2 corresponds to the temperature range of $1010-1050^{\circ} \mathrm{C}$, with logarithm of strain rate range of $0.01-0.56 \mathrm{~s}^{-1}$.

\subsection{Microstructural Characteristic of LDX2101 at Dif- ferent Deformation Conditions}

Figure 6(a) shows the characteristic of microcracks generated in flow instability region with a true strain of $0.7\left(\mathrm{~T}=950^{\circ} \mathrm{C}, \varepsilon=0.1 \mathrm{~s}^{-1}\right)$. It is found that the microcracks nucleates at the ferrite/austenite phase boundaries from Fig. 6(a). Figure 6(a) shows that characteristic of the phase boundaries in LDX2101, which contained massive precipitates along microcracks distribution. During hot deforming, brittle massive precipitates precipitate along

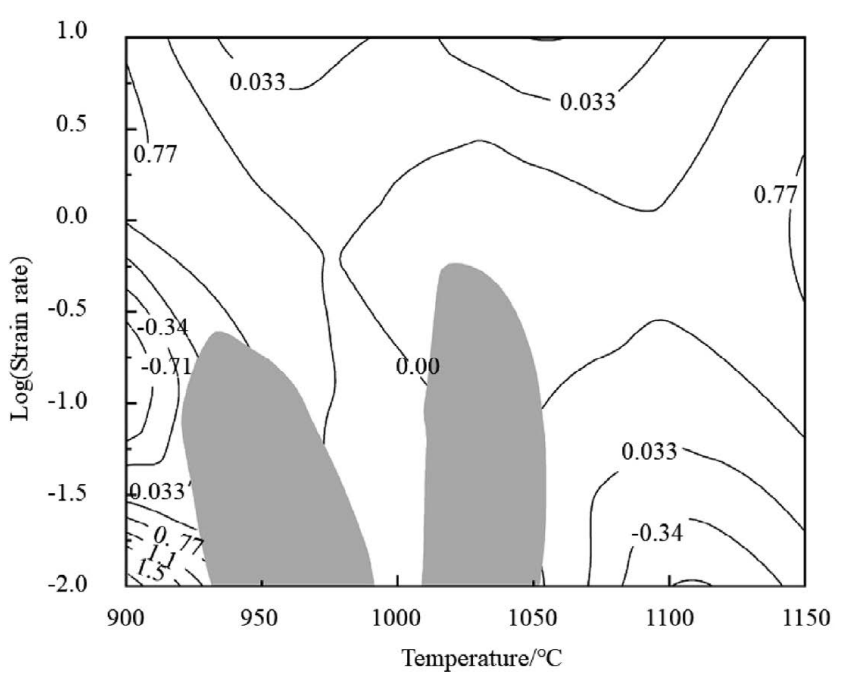

Fig. 5. Processing map according to the plastic work approach at a true strain of 0.7 for LDX2101. 

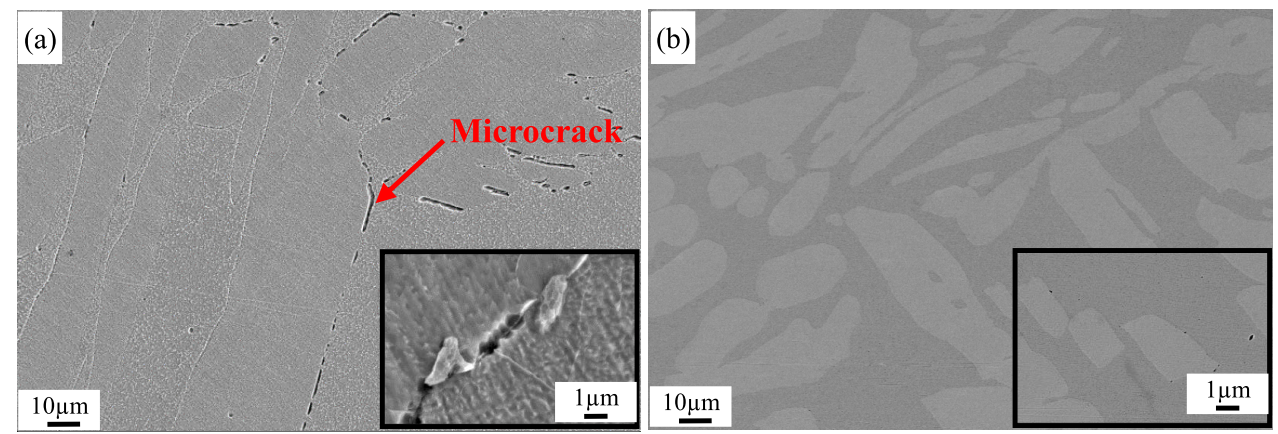

Fig. 6. Microcrack characteristic of LDX2101 deformed at $950^{\circ} \mathrm{C}$ to the true strain of 0.7 with different strain rates (a) $0.1 \mathrm{~s}^{-1}$, (b) $10 \mathrm{~s}^{-1}$. (Online version in color.)
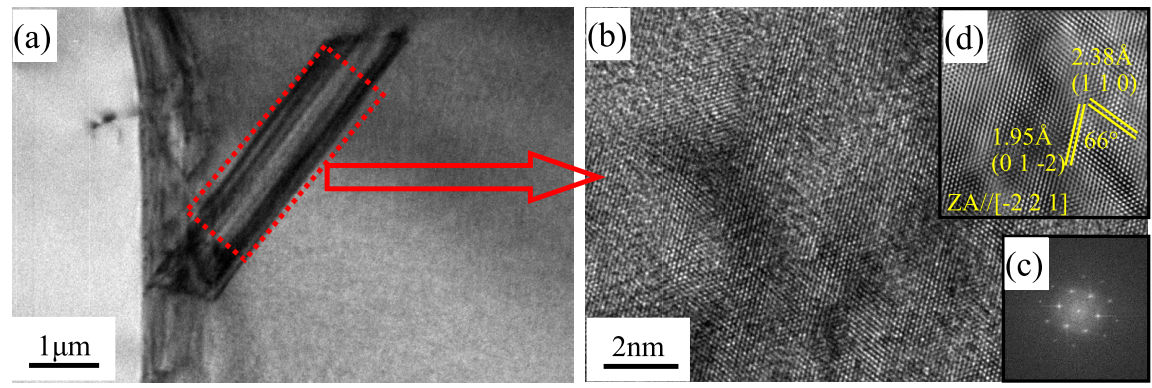

Fig. 7. TEM bright field image of $\mathrm{Cr}_{2} \mathrm{~N}$ massive precipitates in LDX2101 annealed at $950^{\circ} \mathrm{C}$ to the true strain of 0.7 with a strain rate $0.1 \mathrm{~s}^{-1}$. (a) The morphology of $\mathrm{Cr}_{2} \mathrm{~N}$ precipitates, (b) HRTEM image of $\mathrm{Cr}_{2} \mathrm{~N}$ precipitates, (c) FFT diagram of the micrograph in (b), (d) FFT filtered image derived from the image in (b). (Online version in color.)

the phase boundaries due to the suitable conditions (time and temperature). The microcracks begin to nucleate due to weak coordination between brittle precipitates and ferrite/ austenite phase boundaries. However, the microcracks are not found in flow stability region $\left(\mathrm{T}=950^{\circ} \mathrm{C}, \varepsilon=10 \mathrm{~s}^{-1}\right)$ which is shown in Fig. 6(b). It can be seen from Fig. 6 that the processing map has a ability to predict the hot deformation behavior of LDX2101 during hot compression tests.

High resolution transmission electron microscope (HRTEM) imaging was performed to identify the crystal structure of these massive precipitates. Figure 7 shows an HRTEM lattice image of these massive precipitates deformed at $950^{\circ} \mathrm{C}$ with a strain rate range of $0.1 \mathrm{~s}^{-1}$ and strain of 0.7 in the specimens, its fast fourier transform (FFT) image and FFT filtered image with an incident electron is parallel to the $\left[\begin{array}{lll}-2 & 2 & 1\end{array}\right]$ zone axis. Two measured atomic plane distances are $2.38 \AA$ and $1.95 \AA$ with an angle of $66^{\circ}$. This result is in good agreement with the hexagonal structure $\mathrm{Cr}_{2} \mathrm{~N}$. The Mo content in LDX2101 is low compared to conventional duplex stainless steel DSS2205; thus, the precipitation of the $\sigma$-phase, which contains high $\mathrm{Cr}$ and Mo, was highly suppressed in LDX2101. The C content in LDX2101 is also relatively low; thus, the precipitation of $\mathrm{M}_{3} \mathrm{C}$ or $\mathrm{M}_{23} \mathrm{C}_{6}$ was also suppressed. However, the $\mathrm{Cr}_{2} \mathrm{~N}$ precipitates were promoted by the relatively higher content of $\mathrm{N}$ in LDX2101. ${ }^{33)}$ The HRTEM analysis (Fig. 7) confirms these results. This result is also in good agreement with the calculated value by using the JMAT software below $1000^{\circ} \mathrm{C}^{34)}$

To further explore the underlying reasons for the different deformation mechanisms at different strain rates in LDX2101 with different $\mathrm{Z}$ parameters to understand the hot workability of LDX2101, we studied the kernel aver- age misorientation (KAM) maps for ferritic and austenitic regions of the samples deformed at $950^{\circ} \mathrm{C}$ to the true strain of 0.7 with a strain rate of $0.1 \mathrm{~s}^{-1}$ (low- $Z$ parameter) and $10 \mathrm{~s}^{-1}$ (high- $Z$ parameter), which is shown in Fig. 8. The microstructure evolutions from Fig. 8 indicate that KAM develops inhomogeneously due to plastic strain. At the low strain rate, softer ferrite phase deforms predominantly as compared to harder austenite, which can be confirmed from the KAM map of the samples, as indicated in Figs. $8(\mathrm{a})$ and $8(\mathrm{~b})$. It demonstrates that ferrite phase is easier to be soften by DRV due to higher stacking fault energy. ${ }^{4}$ ) The strain distributions between ferrite and austenite phase in LDX2101 during hot deformation vary significantly. Ferrite has a higher stacking fault energy than austenite, therefore the ferrite undergoes DRV during hot deformation process. ${ }^{4)}$ So, ferrite is easier to trigger DRV. However, austenite phase has a lower stacking fault energy, and DRX only occurs when the strain in austenite exceeds a critical value, therefore most of the strain is concentrated in ferrite phase. As strain rate increases, DRV and DRX are obviously promoted in the ferrite and austenite, respectively, as indicated in Figs. 8(c) and 8(d). The frequency of entirely blue (KAM values below $1^{\circ}$ ) in the austenite deformed at $0.1 \mathrm{~s}^{-1}$ is lower than that at $10 \mathrm{~s}^{-1}$, which demonstrate that DRX is more sufficient at higher strain rate. Based on the distribution curves of KAM in austenite from Fig. 8(e), the peak value increases and the whole curve shifts to the lower KAM value with increasing the strain rate, which indicating that DRX is accelerated at higher strain rate.

Consequently, the increasing of strain rate promotes the DRX due to increasing the extra stress, the restoration processes restrains the precipitation of precipitates. Dynamic softening mechanism (e.g. DRV or DRX) is one of the most 

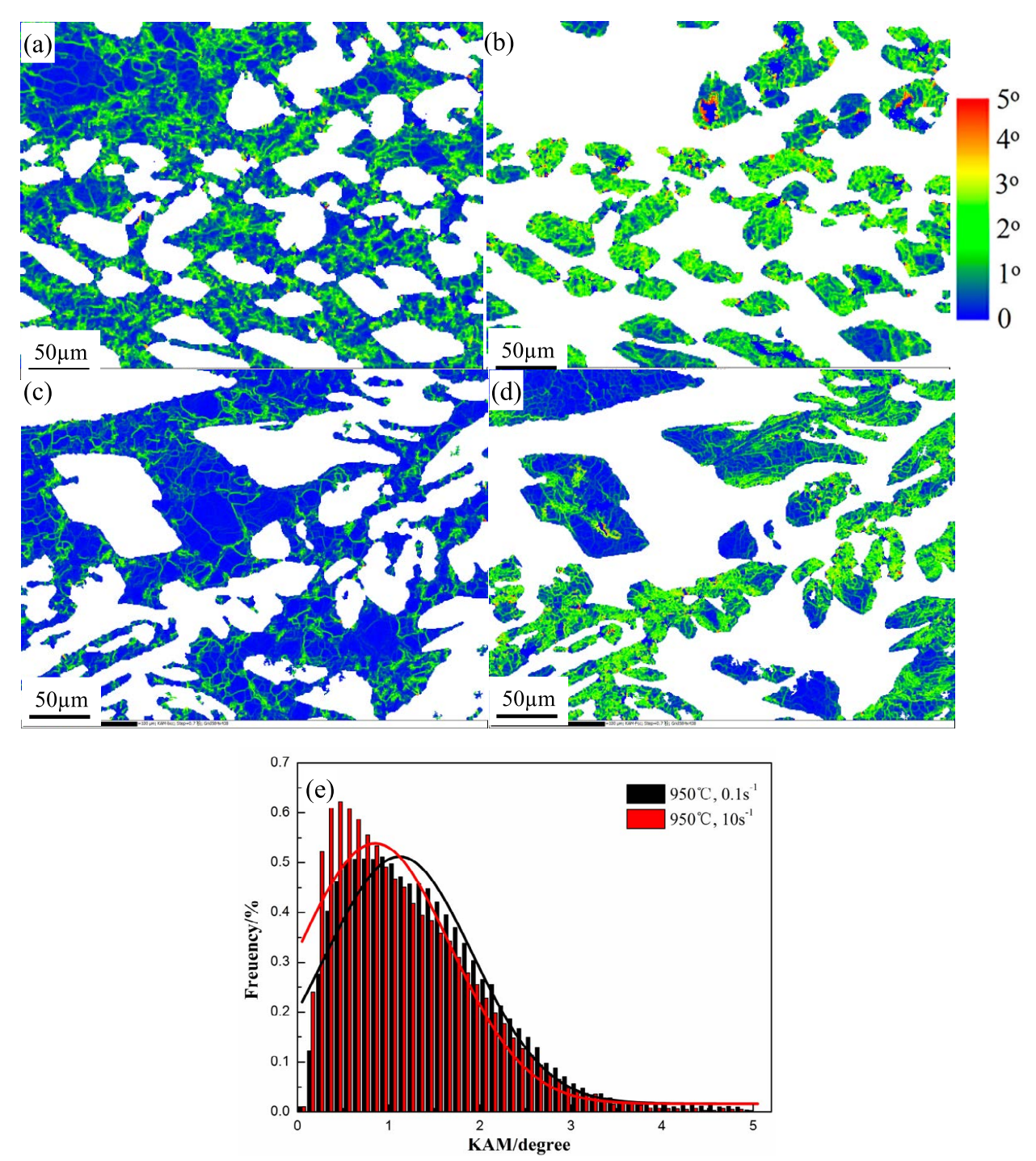

Fig. 8. KAM maps and its distribution maps of LDX2101 after hot deformation at $950^{\circ} \mathrm{C}$ to the true strain of 0.7 with different strain rates (a) and (c) ferrite regions of the samples deformed at $0.1 \mathrm{~s}^{-1}$ and $10 \mathrm{~s}^{-1}$, (b) and (d) austenite regions of the samples deformed at $0.1 \mathrm{~s}^{-1}$ and $10 \mathrm{~s}^{-1}$, (e) distribution curves of KAM in austenite. (Online version in color.)
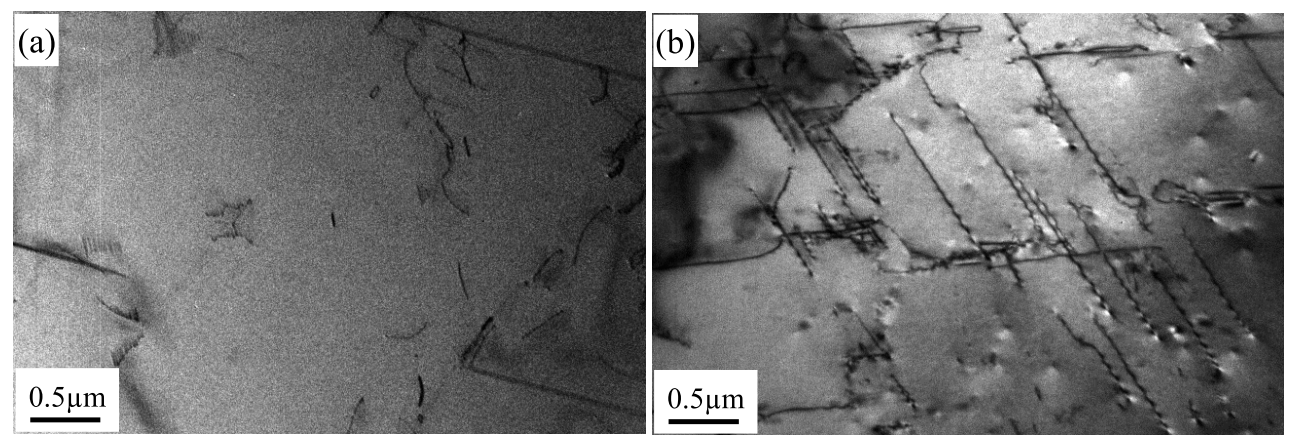

Fig. 9. Dislocation evolutions of LDX2101 in austenite after hot deformation at $950^{\circ} \mathrm{C}$ to the true strain of 0.7 with different strain rates (a) $0.1 \mathrm{~s}^{-1}$, (b) $10 \mathrm{~s}^{-1}$.

effective power dissipation mechanisms in the hot deformation of alloys, which increases the proportion of the energy consumed in structural transformation and decreases the stress concentration in the alloys. ${ }^{35)}$ Moreover, it is generally accepted the fact that the activation energy $Q$ in austenite is higher in ferrite in hot deformation. This indicates that the flow stress of austenite is much higher than ferrite. Thus, strain partitioning usually occurs in a duplex microstruc- ture when the strain is mostly accommodated by the ferrite phase at the early stage of deformation with a low strain rate (low- $Z$ parameter). Further increasing the strain to $10 \mathrm{~s}^{-1}$ (high- $Z$ parameter), the strain starts to transfer from ferrite into austenite. According to the calculation results by using the JMAT software and TEM results, the $\mathrm{Cr}_{2} \mathrm{~N}$ precipitates can rapidly precipitate along two phase boundaries in the process of hot deformation below $1000^{\circ} \mathrm{C}$. The high strain 
rate hinders the precipitation of massive $\mathrm{Cr}_{2} \mathrm{~N}$ precipitates due to the less response time, which enhance the finishing temperature. Moreover, when a higher strain rate is applied, the higher degree of dynamic softening in the ferrite and austenite phase enhances the deformation coordination between the two phases at low temperature stage (below $1000^{\circ} \mathrm{C}$ ). In conclusion, the cracks are more likely to initiate in the phase boundaries during hot deformation below $1000^{\circ} \mathrm{C}$ due to the precipitation of $\mathrm{Cr}_{2} \mathrm{~N}$ precipitates.

Figure 9 shows their dislocation microstructures of austenite phase in $\mathrm{LDX} 2101$ annealed at $950^{\circ} \mathrm{C}$ to the true strain of 0.7 with a strain rate of $0.1 \mathrm{~s}^{-1}$ and $10 \mathrm{~s}^{-1}$, respectively. The austenite phase exist high number density of dislocations at high strain rate, while the number of dislocations at low strain rate is little in austenite. It further demonstrates that the strain transfer into austenite promptly with increasing the strain rate by DRX. Totally, it is favourable to the strain relaxation in the interface and makes the subsequent the deformation coordination of the two phases easier with increasing the strain rate and temperature. Thus, the flow stability of LDX2101 in hot deformation is mainly affected by the degree of dynamic softening and the strain partitioning in each constituent phase, the precipitation rate and temperature of $\mathrm{Cr}_{2} \mathrm{~N}$ precipitates and the hot workability can be optimised by controlling the temperature and strain rate. The optimum hot processing parameters for LDX2101 are found to be in a strain rate range of $0.01-10 \mathrm{~s}^{-1}$ with the temperature range of above $1050^{\circ} \mathrm{C}$ and strain rate of $0.8-10 \mathrm{~s}^{-1}$.

\section{Conclusions}

Hot deformation behaviour of LDX2101 has been studied by investigating the microstructural evolution, flow curves, and processing map during hot compressive tests. The following conclusions are obtained:

(1) High-temperature deformation behavior of the samples strongly depended on deformation temperature and strain rate. The peak and steady-state stresses increased with increasing strain rate and decreasing deformation temperature. The flow curve exhibited significant waviness at strain rate of $10 \mathrm{~s}^{-1}$.

(2) The softening mechanism occurring in the constituent phases differs from each other in LDX2101 during hot deformation. Accordingly, the soft phase ferrite softens by DRV, while the austenite only softens by DRX.

(3) Brittle $\mathrm{Cr}_{2} \mathrm{~N}$ precipitates exist along the ferrite/austenite phase boundaries, which act microcracks initiation position due to the weak deformation coordination between $\mathrm{Cr}_{2} \mathrm{~N}$ precipitates and ferrite/austenite phases.

(4) The deformation parameters and flow behavior significantly affect the hot workability of the samples. When strain rate decreases at low temperature stage, lacks of sufficient extra stress and the precipitation of $\mathrm{Cr}_{2} \mathrm{~N}$ precipitates deteriorates the hot workability of the LDX2101 and causes the microcracks formation at $950^{\circ} \mathrm{C}$ with a strain rate of $0.1 \mathrm{~s}^{-1}$. Overall, it can be seen that the optimum hot processing parameters for LDX2101 are found to be in a strain rate range of $0.8-10 \mathrm{~s}^{-1}$ with the temperature range of $900-1050^{\circ} \mathrm{C}$ and strain rate of $0.01-10 \mathrm{~s}^{-1}$ with the temperature range of above $1050^{\circ} \mathrm{C}$ from hot processing map.

\section{Acknowledgments}

This research is supported by the China Postdoctoral Science Foundation funded project (2018M641699).

\section{REFERENCES}

1) L. Ma, S. S. Hu and J. Q. Shen: J. Mater. Eng. Perform., 26 (2017), 250 .

2) S. Mostafaee, M. Andersson and P. G. Jonsson: Ironmaking Steelmaking, 38 (2011), 90.

3) J. M. Cabrera, A. Mateo, L. Llanes, J. M. Prado and M. Anglada: J. Mater. Process. Technol., 143-144 (2003), 321.

4) Z. H. Feng, J. Y. Li and Y. D. Wang: Steel Res. Int., 88 (2017), 1700177.

5) J. O. Nilsson: Mater. Sci. Technol., 8 (1992), 685.

6) A. Iza-Mendia, A. Pinol-Juez, J. J. Urcola and I. Gutierrez: Metall. Mater. Trans. A, 29 (1998), 2975.

7) Y. Fang, Z. Liu and G. Wang: J. Iron Steel Res. Int., 18 (2011), 58.

8) R. Strubbia, S. Hereñú, M. C. Marinelli and I. Alvarez-Armas: Mater. Sci. Eng. A, 659 (2016), 47.

9) Y. L. Fang, Z. Y. Liu, H. M. Song and L. Z. Jiang: Mater. Sci. Eng. A, 526 (2009), 128.

10) E. Evangelista, H. J. McQueen, M. Niewczas and M. Cabibbo: Can. Metall. Q., 43 (2004), 339.

11) A. Dehghan-Manshadi and P. D. Hodgson: J. Mater. Sci., 43 (2008), 6272.

12) N. D. Ryan and H. J. McQueen: J. Mater. Process. Technol., 21 (1990), 177.

13) L. Chen, X. C. Ma, X. Liu and L. M. Wang: Mater. Des., 32 (2011), 1292.

14) M. Faccoli and R. Roberti: J. Mater. Sci., 48 (2013), 5196.

15) Y. Han, D. N. Zou, Z. Y. Chen, G. W. Fan and W. Zhang: Mater. Charact., 62 (2011), 198.

16) N. Haghdadi, P. Cizek, H. Beladi and P. D. Hodgsn: Acta. Mater., 126 (2017), 44.

17) O. Balancin, W. A. M. Hoffmann and J. J. Jonas: Metall. Mater. Trans. A, 31 (2000), 1353.

18) D. N. Zou, K. Wu, Y. Han, W. Zhang, B. Cheng and G. J. Qiao: Mater. Des., 51 (2013), 975.

19) G. W. Fan, J. Liu, P. D. Han and G. J. Qiao: Mater. Sci. Eng. A, 515 (2009), 108.

20) Y. Y. Liu, H. T. Yan, X. H. Wang and M. Yan: Mater. Sci. Eng. A, 575 (2013), 41.

21) K. W. Wong, C. H. Shek, W. Zhang and J. K. L. Lai: Mater. Lett., 62 (2008), 3991.

22) J. A. Jiménez, G. Frommeyer, M. Carsí and O. A. Ruano: Mater. Sci. Eng. A, 307 (2001), 134

23) A. Dehghan-Manshadi, M. R. Barnett and P. D. Hodgson: Metall. Mater. Trans. A, 39 (2008), 1359.

24) Y. H. Liu, Y. Q. Ning, Z. K. Yao, H. Z. Guo and Y. Nan: J. Alloys Compd., 612 (2014), 56.

25) M. Ma, H. Ding, Z. Tang, J. Zhao, Z. Jiang and G. Li: Ironmaking Steelmaking, 43 (2016), 88.

26) S. Kingklang and V. Uthaisangsuk: Metall. Mater. Trans. A, 48 (2017), 95

27) S. Patra, A. Ghosh, V. Kumar, D. Chakrabarti and L. K. Singhal: Mater. Sci. Eng. A, 6600 (2016), 61.

28) Z. H. Feng, J. Y. Li and Y. D. Wang: Int. J. Miner. Metall. Mater., 23 (2016), No. 4, 425.

29) H. Farnoush, A. Momeni, K. Dehghani, J. Aghazadeh Mohandesi and H. Keshmiri: Mater. Des., 31 (2010), 220.

30) Y. Zhao, W. N. Zhang, Z. Y. Liu and G. D. Wang: Mater. Sci. Eng. A, 702 (2017), 279.

31) Y. Han, D. N. Zou, Z. Y. Chen, G. W. Fan and W. Zhang: Mater. Charact., 62 (2011), 198.

32) Y. Prasad, H. L. Gegel, S. M. Doraivelu, J. C. Malas, J. T. Morgan, K. A. Lark and D. R. Barker: Mater. Trans. A, 15 (1984), No. 10, 1883.

33) A. Momeni and K. Dehghani: Mater. Sci. Eng. A, 528 (2011), No. 3, 1448.

34) H. J. Xu, W. Q. Hu, C. Kang, W. J. Li and X. C. Sha: Steel Res. Int., 92 (2021), 2170013. https://doi.org/10.1002/srin.202000264

35) H. Jiang, J. Dong, M. Zhang, L. Zheng and Z. H. Yao: J. Alloys Compd., 647 (2015), 338. 